\title{
Estética y política en la escritura de Pier Paolo Pasolini
}

\section{Aesthetics and Politics in the Writing of Pier Paolo Pasolini}

\section{Raquel Olea}

Departamento de Lingüística y Literatura, Universidad de Santiago de Chile (r). Santiago, Chile.

raquelolea@vtr.net

\section{Resumen}

Este texto se propone establecer relaciones entre Escritos corsarios (1975) y los "apuntes y notas para una novela” publicados póstumamente en 1992 bajo el título de Petróleo. Como un intelectual comprometido con un pensamiento de izquierda, pero también como poeta, cineasta y creador, Pasolini produce una textualidad político-crítica de resistencia a la implantación del capitalismo global. Esta posición se traduce estéticamente en la escritura múltiple (poética, ensayística, narrativa y dramática). Petróleo constituye una novela que elabora estéticamente imaginación política y pensamiento cultural. Este texto trama lenguajes de una y otra escritura para configurar la significación de Pasolini como intelectual y artista comprometido.

Palabras clave: Pasolini, estética, política, crítica, cultura.

\section{Abstract}

This text aims to establish meaningful relationships between Escritos corsarios (1975) and "sketches and notes for a novel", published posthumously in 1992 under the title of Petróleo. As an intellectual committed to a leftist thought, but also as a poet, filmmaker and creator, Pasolini produced a political-critical textuality of resistance to the implementation of global capitalism. This position is reflected in his manifold writing (poetry, essays, fiction and drama) with which he writes Petróleo. This novel elaborates aesthetically political imagination and cultural thought. This text plots languages of this writing to configure the significance of Pasolini as an intellectual and committed artist.

Keywords: Pasolini, Aesthetics, Politics, Critique, Culture. 


\section{Anticipo y compromiso}

Entre enero de 1972 y comienzos de 1975, Pasolini escribe textos de muy distinta factura e intención: narrativa, poesía y guiones. Además, artículos para la prensa y escritos varios que tienen como centro articulador la actualidad política, social y cultural de Italia de los años sesenta y setenta; son textos intensos, polémicos, críticos y políticos; simultáneamente, continúa escribiendo apuntes y notas para lo que llamó "mi proyecto de novela". Asimismo, despliega una fructífera producción cinematográfica: Los cuentos de Canterbury, el documental Las murallas de Sana, Las mil y una noches y Saló o los 120 días de Sodoma son obra de esos años.

Aquí me referiré a sus textos más polémicos: Escritos corsarios (1975) y los apuntes, numerados del 1 al 133, que constituyen el texto de la novela Petróleo, publicada póstumamente en 1992. Intentaré tramar algunos sentidos entre esa conjunción productiva: entre el polemista y el artista, entre su discurso crítico y su discurso estético. ¿Qué cruces, qué lenguajes, qué trascendencia hacia un sentido superior pueden articularse en ambas escrituras? ¿Qué trama de sentido -si es que la hay- puede establecerse entre su producción polémica y su escritura creativa?

Como un intelectual de izquierda, como poeta y creador; como hombre de su tiempo, Pasolini produce una textualidad que presenta un imaginario político y estético que trasciende el contexto que lo hizo posible; su escritura no sólo representa una visión del mundo previamente razonada, sino que produce otros imaginarios políticos y sociales en los que podemos leer hoy una concepción de mundo que, además de ser profundamente crítica de su época, anticipa cambios que constituyen experiencias contemporáneas. Leído desde la actualidad, Pasolini emerge como un visionario que en su época previó y pudo articular en una textualidad múltiple lo que hoy se reconoce como el presente de la humanidad. El compromiso discursivo de su particular comparecencia pública (como escritor comprometido) configura una ciudadanía artística de singular factura ética.

Situado en la encrucijada de un cambio cultural -antropológico, ha dicho el propio Pasolini-, con un carácter polemista activo, contestatario, sin lugar a negociaciones con el "Nuevo Poder" - "escribo Poder con P mayúscula" (Escritos corsarios 59), dice-, haciéndose cargo de lo aún no reconocible en la transformación cultural que anuncia, Pasolini emerge como un sujeto indomesticado, radicalmente en riesgo. "Mi visión puede ser la de un artista o la de un loco como pretende la burguesía" escribe en el artículo "El verdadero fascismo y por tanto el verdadero antifascismo" (Escritos corsarios 60), defendiéndose de la acusación de esteticismo. Asume la actitud intelectual de un sujeto que posee el saber de una amenaza, de una catástrofe que debe darse a conocer, que debe ser anunciada. De ahí el enunciado de la última entrevista que le realizara Furio Colombo, "todos estamos en peligro" (“Todos estamos”).

Pasolini se sitúa y habla desde el estatuto de un escritor, un cineasta, un poeta: un artista pensante. El artículo "La novela de las matanzas" (Escritos corsarios 96) 
comienza con una afirmación fuerte: "Lo sé". Luego continúa iniciando cada uno de los párrafos del artículo con una fórmula insistente que reitera su afirmación inicial: "Sé los nombres de los responsables de lo que se llama golpe", "[s]é los nombres de los responsables de las matanzas de Brescia," "[s]é los nombres del grupo de poderosos que con la ayuda de la CIA", etcétera, hasta concluir: "Lo sé porque soy un intelectual, un escritor que intenta seguir todo lo que sucede, conocer todo lo que escribe, imaginarse todo lo que no se sabe o que se calla; que coordina hechos incluso lejanos" (Escritos corsarios 97). La cita autoconsigna para sí la condición de sujeto de un saber que procede de su profesión de escritor. El artículo se construye literariamente, como un poema -o una letanía- que sitúa la convicción de una posición de sujeto que sigue, imagina, conoce y descubre tanto lo que se dice como lo que no se dice. El enunciado cobra sentido en su declaración de no callar, articulando ahí, en el decir de lo que se calla, su política intransable de "escritor comprometido" (J. P. Sartre). La confianza en su calidad de escritor está centrada en la literariedad de su lenguaje: figuraciones, imágenes, metáforas, reiteraciones, insistencias que le confieren a su escritura una particularidad a la que él acude explícitamente en sus escritos políticos, otorgándoles un plus de densidad estética: "Me explicaré mejor volviendo a mi modo acostumbrado de hablar, o sea el del literato" (Escritos corsarios 218). Estas referencias a lo literario de su escritura política tienen su contrapunto en lo político de su escritura creativa, de su lenguaje estético. Tanto sus novelas como sus films construyen una narrativa en que cuerpo, deseo erótico y voluntad de poder traman conductas y lenguajes de personajes que, en diversos niveles, siempre interrogan las formas y los modos de dominio social.

Hablar de Pasolini hoy, a casi cuarenta años de su trágica muerte, es hablar de un anticipado, uno que con lucidez profética pudo articular en lo diverso de sus lenguajes un pensamiento crítico que excede la contingencia de su tiempo. Al situar en la centralidad metropolitana el dominio de las culturas periféricas, localizó en Roma, como significante del poder, la articulación de un modelo único que, según él, no es otro que el de "la ideología hedonista del consumo y de la consiguiente tolerancia modernista del tipo americano" (Escritos corsarios 54). Esta situación habría traído lo que él llamó una "mutación antropológica" en la que "los hombres son conformistas e iguales los unos a los otros según un código interclasista (estudiante igual a obrero, obrero del norte igual a obrero del sur)" (66). Petróleo inicia su escritura desde la conciencia de esa centralidad de poder y dominio sobre lo local que significa Roma, la metrópoli: "Naturalmente estamos en Roma, la Roma de finales de los años cincuenta" (43), para agregar: "A la recherche, comme a la recherche: recuerdo aquellas recepciones" (127), refiriéndose a las fiestas romanas.

Roma opera como significante de un centro global. Desde allí se producen en la novela los desplazamientos que, por medio del tópico del viaje y gracias a la ficcionalización de diversas narrativas, le permitirán elaborar las obsesiones, pasiones y recurrencias presentes en la mayoría de su producción: mirar hacia el pasado, 
descubrir otredades de sujeto, encontrar lenguajes perdidos, interrogar la sexualidad dominante, dar libre curso a la pluralidad del deseo.

Según sus editores, la edición de Petróleo, ocurrida póstumamente, procede de: la transcripción del mecanoescrito, página a página (incluidas las hojas de anotaciones manuscritas, en su orden original, eliminando sin indicación algunas palabras, frases o porciones del texto evidentemente suprimidas por el autor (mediante tachaduras o notas explícitas). Por lo tanto, la presente transcripción refleja fielmente el manuscrito de la novela (Petróleo v).

Más allá de los géneros en que se realice la escritura, su tono directo, apelativo, comunica y reflexiona; imagina estratos y niveles que cruzan lo real y lo simbólico. El autor se disemina en múltiples posiciones de sujeto: lúdico, pensante, satírico, violento, radical, extremo; así, atraviesa formas y registros escriturales en que imaginación y pensamiento confluyen en una propuesta de pensamiento social y cultural elaborado estéticamente.

\section{Un poder genocida}

En julio de 1973 (dos meses antes del golpe militar en Chile), Pasolini escribe: "ha comenzado uno de los periodos de reacción más violentos y quizás más definitivos de la historia" (Escritos corsarios 35). La naturaleza exterior de este cambio la reconocemos, pero la naturaleza profunda nos es irreconocible, porque es "en realidad una revolución de derechas" (35). Su posición es radical, apocalíptico en su visión de la sociedad de masas y la sociedad de consumo que abarca la economía, la cultura y las costumbres. La identidad de esta situación mundial que él ha denominado como "Nuevo Poder" es aún incipiente: no puede precisarla, solo sabe que posee vagamente rasgos "modernos", debidos a la tolerancia y a una ideología hedonista, perfectamente autosuficiente. Aunque también tiene rasgos feroces y sustancialmente represivos, la tolerancia en realidad es falsa porque ningún hombre ha tenido que ser tan normal y conformista como el consumidor; y en cuanto al hedonismo, este encubre evidentemente una decisión de ordenarlo todo con una crueldad jamás conocida por la historia. De modo que este nuevo poder aún no representado por nadie y debido a un cambio de la clase dominante es en realidad -si queremos conservar la vieja terminología- una forma total de fascismo. Pero este poder también ha "homologado" culturalmente a toda Italia: se trata, pues, de una homologación represiva, aunque se haya obtenido a través de la imposición del hedonismo y de la joie de vivre.

En el artículo "El verdadero fascismo y por tanto el verdadero antifascismo", se concentra -en conceptos como la homologación, el hedonismo, el consumismo, el nuevo fascismo- la visión y el pensamiento político que desplegará con la ferocidad de un sujeto, en la mayoría de los artículos de Escritos corsarios. La calificación de la 
situación de lo nuevo como "un todo (industrialización total), y además como un todo no italiano" transnacional)" (Escritos corsarios 59) lo sitúa a él mismo en un afuera, como un autoexcluido, en la posición de sujeto trágico, quien desde su saber se halla solo, sin alianzas ni contención política. Después de la publicación de Escritos corsarios, el autor quedará a la intemperie, excluído, en la experiencia de la pérdida de todo lo que sostenía su proyecto político y cultural: pérdida de los lenguajes dialectales, de las culturas rurales, de la pureza del deseo y los cuerpos, de la confianza en las culturas periféricas, en el mundo anterior al libre mercado; vida propia, diversidad cultural, creatividad e ingenio surgidos de saberes arcaicos y conocimientos fundados en la experiencia de la comunidad. Vida "esencialmente libre", dice, mientras hoy se homologan destructivamente diferencias y riquezas culturales. El espíritu de la TV, al que califica de autoritario y represivo: "el nuevo fascismo, a través de los nuevos medios de comunicación y de información (especialmente, y sobre todo de la televisión)" (43). Los textos de Escritos corsarios anticipan el advenimiento de una cultura violenta y totalitaria. En una lectura crítica y fina de los signos corporales y lingüísticos de los años sesenta y setenta, Pasolini advierte los efectos biopolíticos del neoliberalismo que cobra en el comportamiento del cuerpo y el lenguaje la adhesión a la ideología del hedonismo que transforma al sujeto contemporáneo. La represión del consumo es peor que el fascismo, indica.

Militante del partido comunista, Pasolini había confiado en el marxismo y también en las tradiciones humanistas representadas por el cristianismo progresista de la iglesia, es decir, en la construcción de formas de armonía social. Sin embargo, la constatación del triunfo de los valores burgueses y del aburguesamiento interclasista que la nueva cultura ofrece altera sus expectativas y lo conduce a un escepticismo y un malestar radical frente a su tiempo.

Didi-Huberman ha trabajado "El artículo de las luciérnagas" -incluido en Escritos corsarios, y que fue publicado anteriormente con el nombre de "El vacío de poder en Italia” - para instalar la pregunta por la desesperanza política en Pasolini. En dicho artículo, el italiano construye una definición poético-literaria de las transformaciones que opera la industrialización en la vida natural. "A inicios de los años sesenta, por la polución del aire y sobre todo en los campos por la contaminación del agua (los azules ríos y las balsas transparentes) empezaron a desaparecer las luciérnagas" (131). A propósito de esta imagen, Pasolini reflexiona sobre una pugna cultural entre las formas de alumbrar la oscuridad. Su escritura trabaja la metáfora de la luz en la imagen de las luciérnagas exterminadas por los focos y reflectores del poder. Al operar invasivamente en los espacios, los grandes reflectores actúan como aniquiladores de las pequeñas intermitencias de otras luces. Didi-Huberman señala que con la imagen de la extinción de las luciérnagas Pasolini se refiere a la realidad del pueblo que, a sus ojos, está en trance de desaparecer.

Su tragedia es que él, en medio de esa realidad, se ve obligado a abjurar de lo que había constituido la base de su energía poética y cinematográfica. Didi-Huberman 
se pregunta qué es lo que llevó a Pasolni a desesperar de su tiempo, a manifestar un escepticismo tan radical frente a lo que él llamó "la destrucción del humanismo", que es ese algo central en él, que no está, que ya no ve y que lo ha hecho perder la esperanza política.

Pasolini quizás perdió la esperanza en las formas y alianzas de la política de su tiempo. Sin embargo, la continuidad y cohesión de su trabajo intelectual, la conjunción de la política y lo político que su obra expresa insistentemente; la resistencia crítica inclaudicable al "Nuevo Poder" y, por otra parte, los riesgos y experimentaciones estéticas que asume, la valoración de la lenguas dialectales, la belleza de los cuerpos no contaminados por el mercado, la vitalidad de la alegría, los mundos periféricos que exhibe y ama; todo ello forma parte del legado de una subjetividad política y pensante que nos apela a mirar en esos signos hoy lo que la cultura de masas ha destruido.

\section{Petróleo}

Pasolini no alcanzó a entregar Petróleo a un editor, pero envió el manuscrito a su amigo Alberto Moravia con una nota: "para que me des un consejo", le pide, y advierte:

Es una novela, pero no está escrita como están escritas las (verdaderas) novelas: su lenguaje es el que se utiliza para los ensayos, para determinados artículos periodísticos, para las reseñas, para las cartas privadas y también para la poesía; raros son los fragmentos que se puedan decir (decididamente) narrativos [...] y por otra parte hay también una cita simbólica en este sentido: Il voyager... que evocan más bien el lenguaje de las adaptaciones o de los guiones que el de las novelas clásicas: vale decir, que se trata de "pasajes narrativos propiamente dichos” elaborados de propósito para evocar la novela [sic] (Petróleo 564).

También refiere a la relación con el lector: "le he hablado al lector en cuanto yo mismo, en carne y hueso, tal como te escribo esta carta, o como a menudo he escrito mis poesías en Italiano. He hecho de la novela no sólo un objeto para el lector, sino para mí: he puesto dicho objeto entre el lector y yo, y juntos hemos discutido (tal como se puede hacer a solas, escribiendo)" (Petróleo 564-5).

Las palabas del autor hablan de la propiedad de un texto singular en su estructura, en sus lenguajes, y también en la propuesta de relación escritor/lector, al explicitar la heterodoxia de un texto que antes de situarse en la estructura de un género determinado, prefiere evocar y hacer converger diferencias. El decir de Petróleo es heterogéneo y múltiple. Su lectura propone una síntesis del pensamiento estético de su autor. Una poética que conjuga diversas formas de escritura con una política articuladora de su pensamiento cultural.

Escrituras diversas en distintas estructuras que organizan movilidades estéticas en lenguajes reminiscentes, que atraviesan registros de la oralidad popular, la solem- 
nidad de la tragedia, la alegría de la fiesta y la sexualidad libre, para establecer con el lector el sentido profundo y trágico del arte. Texto proliferante en que el autor despliega y cruza excesos de tropos literarios, producciones de sujetos, escenificaciones de lo mítico. La violencia de la crítica al presente se entrelaza con las referencias y citas que van desde lo moderno a lo arcaico. La estructura viene a ser un modo de desordenar lo estratificado por épocas, por tiempos: un artefacto en el cual, como en un palimpsesto de hechos, lenguajes y figuraciones, se explicita el espíritu lúdico y la versatilidad de un artista que se desplaza por las mayores tradiciones literarias de las culturas que cruzan lo europeo, lo asiático y lo africano. Su trabajo con la cita es de interrupción, irrupción: el artista las vuelve contemporáneas, las evoca.

El recurso del viaje permite al autor el juego de la doble referencialidad personal e histórica; hace posible encuentros, conexiones con otras realidades gozosas, propias de tiempos en que la experiencia sexual, el conocimiento del cuerpo y la imaginación iluminan otras formas del deseo. El imaginario del texto habilita una mirada interrogante - pero sin melancolía - al vacío que ha dejado la desaparición de la Italia rural y paleo-industrial que Pasolini escribe en sus textos políticos.

Petróleo adquiere la dimensión de un texto monumental. La ferocidad de la escritura de Escritos corsarios, su escepticismo y desesperanza, alcanza en la estética de la novela tonalidades más múltiples, dispersas, ambiguas y esperanzadoras.

Si Pasolini no pudo articular en Escritos corsarios una respuesta política al carácter de genocidio cultural que atribuye a la sociedad de consumo, es en las dimensiones simbólicas de su trabajo estético donde permanece, como una salida posible, aquello que sus escritos políticos acusan como falta. En Petróleo, la violencia de la escritura de Escritos Corsarios es suavizada por la imaginación poética, y ofrece en el campo simbólico la salvación de una fe que perdura en lo que allí se escribe como diferencia crítica, en medio del vacío cultural de lo que el escritor italiano anunció como cambio antropológico operado por "el nuevo Poder".

Sobre el título de la novela Petróleo, Pasolini dice: "Mis ojos cayeron por azar sobre la palabra Petróleo en un articulillo creo que de L'Unità y sólo por haber pensado en la palabra Petróleo como título de un libro sentí luego el impulso de pensar la trama de dicho libro" (Petróleo 563).

Sobre el término, se lee en el diccionario de la RAE: "líquido oleaginoso que se extrae de lechos geológicos continentales o marino". La indicación apela a un yacimiento en lo profundo: el signo podría abrir una ruta hacia el sedimento, a lo que debe ser políticamente extraído de la "fuerza del pasado", cuando el presente comparece vaciado de sentido.

Pasolini fusionó en su escritura, filmografía y vida su formación y trayectoria de humanista crítico. La pérdida de confianza en la política no le resta compromiso (político) al trabajo que desarrolló como artista, un proyecto de libertad y descosificación lo humano, que ve tanto en el cine como en la escritura el lugar de su expresión estética. Siempre estuvo situado en ambos lugares. Así lo dice: "Si he elegido ser 
cineasta al mismo tiempo que escritor, se debe al hecho de que en lugar de expresar esta Realidad a través de estos símbolos que son las palabras, he preferido el cine como medio de expresión: expresar la Realidad a través de la Realidad" (cit. en Naldini 213). Petróleo, en tanto apuntes inconclusos para un proyecto de escritura que Pasolini pensó como novela -y así fue publicada-, cumple el deseo de su autor de expresar poética y políticamente la realidad.

\section{Referencias}

Didi-Huberman, Georges. Supervivencia de las luciérnagas. Madrid: Abada, 2012. Medio impreso.

Naldini, Nico. Pier Paolo Pasolini. Barcelona: Circe, 1992. Medio impreso.

Pasolini, Pier Paolo. Accattone. Mamma Roma. Buenos Aires: Sudamericana, 1965. Medio impreso.

---. Petróleo. Barcelona: Seix barral, 1993. Medio impreso.

---. Una vida violenta. Barcelona: Seix Barral, 1993. Medio impreso.

---. La religión de mi tiempo. Barcelona: Icaria, 1997. Medio impreso.

---. Poesía en forma de rosa. Madrid: Visor, 2002. Medio impreso.

---. Escritos corsarios. Barcelona: Planeta, 1983. Medio impreso. 